\title{
Spatial-temporal analysis and risk characterisation of pesticides in Alpine glacial streams ${ }^{\text {और }}$
}

\author{
C. Rizzi, A. Finizio, V. Maggi, S. Villa* \\ Dept. of Earth and Environmental Sciences, University of Milano - Bicocca, Piazza della Scienza 1, 20126, Milano, Italy
}

\section{A R T I C L E I N F O}

\section{Article history:}

Received 4 December 2018

Received in revised form

20 February 2019

Accepted 21 February 2019

Available online 26 February 2019

\section{Keywords:}

Pesticides

Glacial meltwater

Ice core

Environmental risk assessment (ERA)

Alps

\begin{abstract}
A B S T R A C T
We analysed the spatial and temporal distribution of a selection of pesticides in Alpine glaciers used on the Po Plain in Northern Italy, near the Alps. By analysing a 102-m ice core taken from the Lys Glacier (Monte Rosa massif, Italy), we highlight historical contamination from the insecticide chlorpyrifos and the herbicide terbuthylazine, confirming the role of alpine glaciers as temporal sinks.

In addition, we collected meltwater samples from six glaciers distributed along the Alpine Arc during the summer of 2016, which showed widespread contamination by pesticides. Overall, chlorpyrifos and terbuthylazine dominated the contaminant fingerprint of all of the studied glaciers, with contamination peaks occurring at the beginning of the melting season. This highlights the importance of the mediumrange atmospheric transport of these pesticides in connection with agricultural practices in the areas beneath the Italian Alps, where they are widely applied.

The release of pesticides in meltwater can lead to potential risks to the aquatic ecosystems of headwater streams, as we demonstrate for chlorpyrifos. This suggests that the medium-range atmospheric transport of pesticides should be considered as part of regulations to protect the water quality of these pristine environments.
\end{abstract}

(c) 2019 Elsevier Ltd. All rights reserved.

\section{Introduction}

Evidence of contamination in alpine regions dates back to the early 1990s when Calamari et al. (1991) suggested the potential for high mountains to function as regional "cold traps" for persistent organic pollutants (POPs). Subsequently, this was confirmed by the work of Daly and Wania (2005) who highlighted the potential of mountains to act as regional convergence zones for winds and to produce "altitudinal fractionation" of POPs. There have been numerous studies reporting the presence of POPs in snow, upland lakes, and glacial ice (Villa et al., 2014). In Europe, densely populated areas occur near Alpine regions and this can favour the input of contaminants that are less persistent than POPs, but which are still capable of undergoing regional atmospheric transport (Villa et al., 2003) over distances of up to a few hundred kilometres from their source areas. It is a common belief that currently used pesticides (CUPs) are unlikely to persist in the environment to the same extent as POPs. Indeed, the present authorisation procedures

\footnotetext{
This paper has been recommended for acceptance by Charles Wong.

* Corresponding author.

E-mail address: sara.villa@unimib.it (S. Villa).
}

for agricultural pesticides include an evaluation of the risks that pesticide use poses to non-target organisms living on and at the edge of fields (European Food and Safety Agency (EFSA), 2013). However, some CUPs still exhibit noticeable persistence. This is the case for atrazine, alachlor, metolachlor, chlorpyrifos, diazinon, disulfoton, and chlorothalonil (Muir et al., 2007). Furthermore, the continuous use of CUPs can lead to a pseudo-persistency phenomenon (Daughton, 2003; Mackay et al., 2014a). In addition, most CUPs are water soluble, meaning that they will dissolve in precipitation more readily than the hydrophobic pesticides used in the past. This is particularly relevant for temperate mountainous regions that tend to receive high levels of precipitation, which can favour the wet deposition of CUPs on glaciers. During recent years, it has become increasingly apparent that airborne dispersion of CUPs results in these pesticides entering surface waters and nature reserves in areas relatively far from their areas of use (Guida et al., 2018). Recently, monitoring studies have reported the presence of CUPs in glacier meltwaters of the Italian Alps (Ferrario et al., 2017a) and in glacial lakes of the Pyrenees (Santolaria et al., 2015). Consequently, there is a need to improve knowledge regarding the level of contamination of European Alpine environments and the potential risks posed to these ecosystems. This is in line with 
Directive 2009/128/EC (European Commission, 2009a) on sustainable use of pesticides.

In this study, a spatial and temporal analysis of pesticide contamination was performed using meltwater samples collected from six alpine glacial streams and a 102-m ice core (Lys Glacier, Monte Rosa massif). Moreover, the risk that the contamination poses for aquatic communities was characterised.

\section{Materials and methods}

\subsection{Sampling area}

The sampling sites in the European Alps (Figure S-1 in SI) were the Lys Glacier (Monte Rosa massif, Western Alps), the Morteratsch Glacier (Bernina Range of the Bündner Alps, Switzerland), the Forni Glacier (Ortles-Cevedale Group), the Tuckett Glacier (Brenta Group), the Presena Glacier (Presenella Group) and the Giogo Alto Glacier (Palla Bianca-Similaun Group). The sampling dates are reported in the Supplementary Information (SI). In each case, 10-L glacier meltwater samples were collected in 2016 using precleaned aluminium cans ( $5 \mathrm{~L}$ and $2.5 \mathrm{~L}$ ), which were kept in a cooler box during transport and were stored at $-20^{\circ} \mathrm{C}$ prior to analysis.

In July 2003, an ice core was collected from the Lys Glacier by drilling to a depth of $102 \mathrm{~m}$. During the drilling operation, all the ice waste was retained in a chamber above the core barrel, ensuring the borehole remained clear. This material (ice chips) was collected and thermally sealed on-site, and subsequently divided into five samples. Further details of the ice core drilling operation and dating are provided in SI.

\subsection{Chemical analysis}

The selection of pesticides listed in Tables $\mathrm{S}-1$ was based on previous experience (Villa et al., 2001; Villa et al., 2003; Villa et al., 2006; Villa et al., 2014; Ferrario et al., 2017a) and the Italian Agricultural Information System sales statistics (SIAN, 2017). Analytical standards were obtained from Dr. Ehrenstofer GmBH (Augsburg, Germany) and Sigma-Aldrich (St. Louis, USA), and all solvents were obtained from Merck (residue analysis grade; Merck Darmstadt, Germany).

Water and ice chip samples were melted at room temperature, filtered using a glass-fibre filter (GFF; $0.45 \mu \mathrm{m}$, Whatman, England), and extracted by means of solid-phase extraction (SPE) using Oasis ${ }^{\circledR}$ hydrophilic-lipophilic balanced (HLB) sorbent (Waters, USA). The extracts were then eluted (under gravity) with $15 \mathrm{~mL}$ of methanol, $20 \mathrm{~mL}$ of acetone:n-hexane (20:80), and $5 \mathrm{~mL}$ of acetone. Extraction from the GFFs was performed using a Soxhlet extractor with n-hexane for $24 \mathrm{~h}$. The extracts were purified using Supelclean $^{\mathrm{TM}}$ ENVI-Carb SPE (Supelco, USA) and they were subsequently eluted (under gravity) with $10 \mathrm{~mL}$ of n-hexane, $10 \mathrm{~mL}$ of $\mathrm{n}$-hexane:ethyl acetate (60:40), and $5 \mathrm{~mL}$ of ethyl acetate.

All extracts, concentrated to $25 \mu \mathrm{L}$ in n-dodecane containing PCB 30 as the internal standard, were analysed using gas chromatography-mass spectrometry (GC-MS; Agilent Technologies, CA, USA) in selected ion monitoring (SIM) mode. Details of the oven program, MS settings, and detection limits are reported in SI.

\subsection{Quality control}

Accuracy and precision were evaluated by spiking each sample with a 10- $\mu \mathrm{L}$ mixture of PCB 40 and PCB 128 from $400 \mathrm{pg} / \mu \mathrm{L}$ stock solution. With the exception of dichlobenil, recoveries were within acceptable accuracy limits (Tables $S-1$ ). Chlorpyrifos was found in the blanks (generated by filling pre-cleaned bottles with $1 \mathrm{~L}$ of
Milli-Q water in the field), which was corrected for by subtracting the average value of $50 \mathrm{pg} / \mathrm{L}$.

\subsection{Risk characterisation}

Risk characterisation was performed using the toxicological exposure ratio (TER) approach (Eq. (1)):

$\mathrm{TER}=\mathrm{EC}_{50, i} / \mathrm{MEC}$

where $\mathrm{EC}_{50, i}$ is the half-maximal effective concentration for the most sensitive aquatic non-target species $i$ (Daphnia magna for insecticides and algae for herbicides), and MEC is the measured environmental concentration (i.e., the level of exposure). $\mathrm{EC}_{50, i}$ data were gathered from the Pesticide Properties DataBase (PPDB; Lewis et al., 2016). According to Regulation 1107/2009 (European Commission, 2009b) for pesticides in the EU market, in the firsttier risk assessment, acceptable risk is indicated where the TER is $>100$ for D. magna and $>10$ for algal organisms.

\section{Results}

\subsection{Pesticides in meltwater samples}

Pesticide concentrations detected in the meltwater (the sum of both the dissolved and sorbed phases) collected from the six Alpine glaciers are reported in Table 1 . Given that there were no replicates of samples, a certain degree of uncertainty is associated with these data.

Fig. 1 shows the fingerprints of contamination (Calamari et al., 1994) for the different sampling sites. Fingerprints were calculated by considering the relative contribution (\%) of each chemical to the overall level of contamination (i.e., the sum of the measured contaminant concentrations).

\subsubsection{Lys Glacier}

Lys Glacier was characterised by the presence of chlorpyrifos (CPY), terbuthylazine (TBZ), metholachlor/s-metholachlor (MTL), and chlorpyrifos-methyl (CPY-m) in both the early and late summer samples. Although the total level of contamination was comparable between the two sampling campaigns, some qualitative differences were identified in the contamination fingerprints. Indeed, the metabolite desethyl-terbutylazine (d-TBZ) was below the detection limit in the meltwater collected during early summer, while it was the most abundant pollutant during late summer $(3.57 \mathrm{ng} / \mathrm{L})$. In contrast, alachlor (ALA) and atrazine (ATR) were only found in the sample gathered at the end of June $(0.59 \mathrm{ng} / \mathrm{L}$ and $0.22 \mathrm{ng} / \mathrm{L}$, respectively).

\subsubsection{Morteratsch Glacier}

The contamination fingerprint of the meltwater from Morteratsch Glacier, which is located further east, was characterised by the presence of CPY. Indeed, TBZ was only found in the sample gathered in July $(\sim 0.8 \mathrm{ng} / \mathrm{L})$. Moreover, a remarkable reduction in CPY concentrations was observed between the beginning and the end of summer ( $15.4 \mathrm{ng} / \mathrm{L}$ and $6.75 \mathrm{ng} / \mathrm{L}$, respectively).

\subsubsection{Forni Glacier}

A similar decreasing trend was observed in the meltwater samples from the Forni Glacier (Table 1), where the CPY concentration was $70 \mathrm{ng} / \mathrm{L}$ in early July, approximately $20 \mathrm{ng} / \mathrm{L}$ in August, and approximately $7 \mathrm{ng} / \mathrm{L}$ in September and October. In addition to CPY, which was the most abundant pollutant in all meltwater samples, MTL, CPY-m, TBZ, and d-TBZ were also detected. Specifically, MTL and CPY-m were detected in the meltwater gathered in 
Table 1

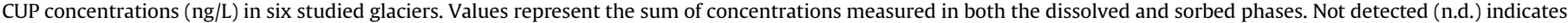
that the chemical concentration was below the detection limit.

\begin{tabular}{|c|c|c|c|c|c|c|c|c|}
\hline \multirow[t]{2}{*}{ Environmental matrix } & \multirow[t]{2}{*}{ Date } & \multicolumn{7}{|c|}{ Active ingredients (ng/L) } \\
\hline & & CPY & CPY-m & TBZ & d-TBZ & MTL & ALA & ATR \\
\hline & & Lys G & & & & & & \\
\hline \multirow[t]{20}{*}{ Meltwater Samples } & $30 / 06 / 2016$ & 3.57 & 0.27 & 1.38 & n.d. & 1.1 & 0.59 & 0.22 \\
\hline & $14 / 09 / 2016$ & 1.90 & 0.46 & 0.72 & 3.57 & 0.86 & n.d. & n.d. \\
\hline & & Mort & acier & & & & & \\
\hline & $06 / 07 / 2016$ & 15.4 & n.d. & 0.8 & n.d. & n.d. & n.d. & n.d. \\
\hline & $15 / 09 / 2016$ & 6.75 & n.d. & n.d. & n.d. & n.d. & n.d. & n.d. \\
\hline & & Forn & & & & & & \\
\hline & $01 / 07 / 2016$ & 70.3 & 1.94 & n.d. & n.d. & 2.19 & n.d. & n.d. \\
\hline & $02 / 08 / 2016$ & 20.7 & 2.56 & 2.27 & n.d. & 1.14 & n.d. & n.d. \\
\hline & $16 / 08 / 2016$ & 17.9 & n.d. & 2.46 & n.d. & n.d. & n.d. & n.d. \\
\hline & $19 / 09 / 2016$ & 7.91 & n.d. & n.d. & 3.57 & n.d. & n.d. & n.d. \\
\hline & $06 / 10 / 2016$ & 6.85 & n.d. & n.d. & 1.21 & n.d. & n.d. & n.d. \\
\hline & & Prese & & & & & & \\
\hline & $13 / 07 / 2016$ & 9.43 & n.d. & 2.96 & n.d. & 4.62 & n.d. & n.d. \\
\hline & $14 / 09 / 2016$ & 13.0 & n.d. & 0.51 & 4.9 & n.d. & n.d. & n.d. \\
\hline & & Tuck & & & & & & \\
\hline & $12 / 07 / 2016$ & 8.33 & n.d. & 1.32 & 3.22 & n.d. & n.d. & n.d. \\
\hline & & Giog & & & & & & \\
\hline & $11 / 07 / 2016$ & 11.7 & n.d. & n.d. & n.d. & 6.81 & n.d. & n.d. \\
\hline & $20 / 09 / 2016$ & 9.76 & n.d. & n.d. & n.d. & 1.48 & n.d. & n.d. \\
\hline & & Lys G & & & & & & \\
\hline \multirow[t]{5}{*}{ Ice chips } & 1990-1992 & 1.31 & n.d. & 1.09 & n.d. & n.d. & n.d. & n.d. \\
\hline & 1993-1994 & 5.50 & n.d. & 0.9 & n.d. & n.d. & n.d. & n.d. \\
\hline & 1995-1996 & 2.29 & n.d. & 1.33 & n.d. & n.d. & n.d. & n.d. \\
\hline & 1997-1999 & 32.8 & n.d. & 1.1 & n.d. & n.d. & n.d. & n.d. \\
\hline & $2000-2002$ & 1.11 & n.d. & 2.17 & n.d. & n.d. & n.d. & n.d. \\
\hline
\end{tabular}

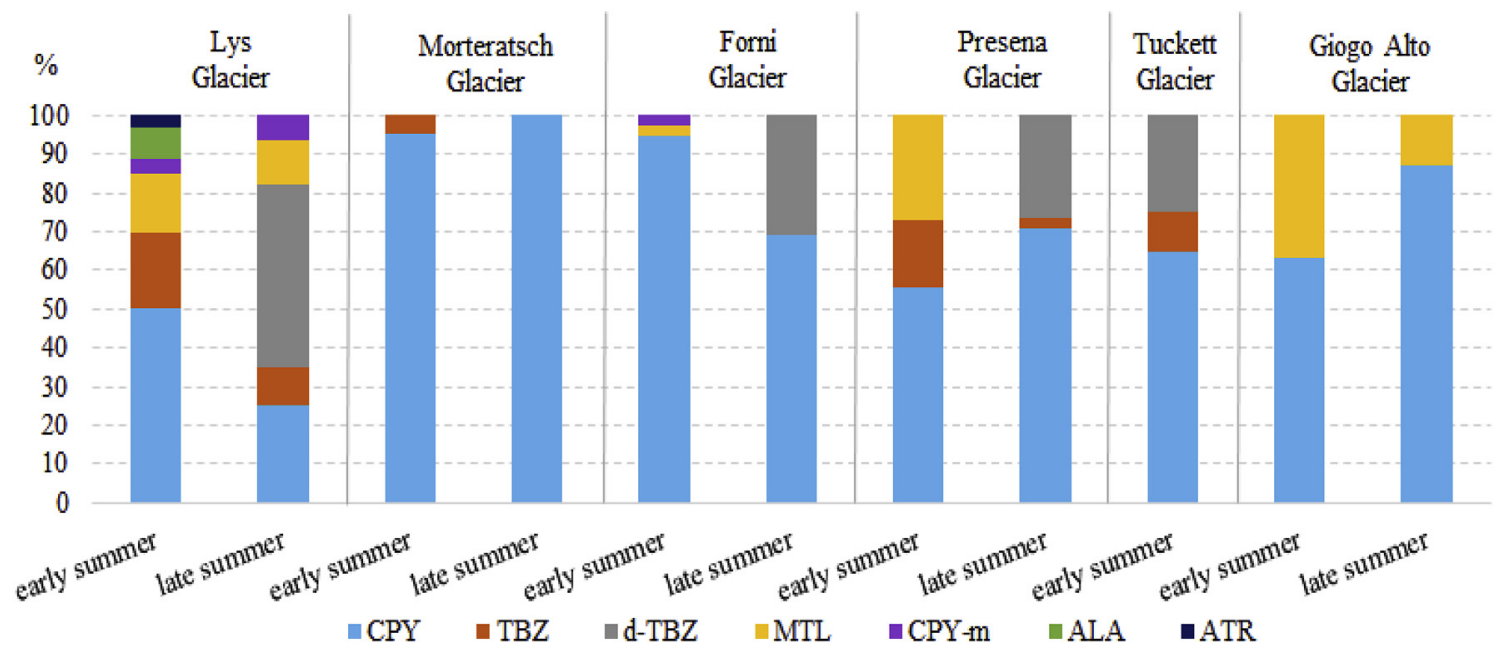

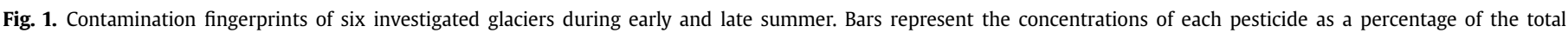
concentrations recorded at each sampling site.

July and early August at concentrations within the range of $1.14-2.19 \mathrm{ng} / \mathrm{L}$ and $1.94-2.56 \mathrm{ng} / \mathrm{L}$, respectively. During the same period, the concentration of CPY-m remained stable, while the concentration of MTL decreased. TBZ was only found in the August samples, with the range of $2.27-2.46 \mathrm{ng} / \mathrm{L}$, while its main metabolite (d-TBZ) was only recorded in the late summer samples. The concentration of d-TBZ was within the range of $1.21-3.57 \mathrm{ng} / \mathrm{L}$ and showed a significant decrease between September and October.

\subsubsection{Presena Glacier}

CPY was the most abundant contaminant in meltwater samples from the Presena Glacier, with concentrations slightly increasing during the sampling interval (ranging from $9.43 \mathrm{ng} / \mathrm{L}$ to $13.0 \mathrm{ng} / \mathrm{L}$ ). The contamination fingerprint for this glacier was also characterised by the presence of MTL, TBZ, and d-TBZ. MTL was only found in early summer, at a concentration of approximately $2.14 \mathrm{ng} /$ L. In contrast, TBZ was recorded during both sampling campaigns, but showed a decreasing trend (from $2.96 \mathrm{ng} / \mathrm{L}$ to $0.51 \mathrm{ng} / \mathrm{L}$ ) that was counteracted by an increase in its metabolite d-TBZ (4.90 ng/L).

\subsubsection{Tuckett Glacier}

The metabolite d-TBZ was detected in an early summer sample from the Tuckett Glacier. In particular, the concentration of d-TBZ (3.22 ng/L) was significantly higher than TBZ (1.32 ng/L) even thought CPY was the most abundant pollutant $(8.33 \mathrm{ng} / \mathrm{L})$. Water from the Tuckett ablation stream was not sampled during late summer because of an absence of surface water during the field survey. 


\subsubsection{Giogo Alto Glacier}

This glacier was characterised by the presence of CPY and MTL during both sampling campaigns. The concentrations of CPY were within the range of 9.76-11.7 ng/L and remained stable. In contrast, the concentrations of MTL significantly decreased from $6.81 \mathrm{ng} / \mathrm{L}$ to $1.48 \mathrm{ng} / \mathrm{L}$ during the same period.

\subsection{Pesticides in ice}

The pesticide concentrations measured in the ice chip samples collected on Lys Glacier during the growing season are reported in Table 1 . These samples were characterised by the constant presence of CPY and TBZ. Other chemicals were always below the detection limit. Levels of CPY were within the range of $1.31-5.50 \mathrm{ng} / \mathrm{L}$ from 1990 to 1996, with concentrations peaking during the period 1997-1999 (up to $32.8 \mathrm{ng} / \mathrm{L}$ ). Levels then decreased during the period 2000-2002, returning to their initial values. The levels of TBZ were approximately $1 \mathrm{ng} / \mathrm{L}$ between 1990 and 1999, and nearly doubled during the period 2000-2002.

\subsection{Risk characterisation}

Table 2 shows the TERs for the detected compounds. In almost all cases, the TER was $>100$ suggesting an acceptable level of risk. As the exception, the TERs for CPY ranged from 1.42 (Forni Glacier) to 52.6 (Lys Glacier), indicating an unacceptable level of risk for aquatic invertebrates.

\section{Discussion}

The concentrations of pesticides detected in samples taken from the six studied glaciers showed different spatial and seasonal patterns. These differences can be explained by agricultural land use on the Po River plain, the meteorological and geographical characteristics of these Alpine areas, and the physical and chemical properties of the compounds. In particular, the following aspects explain the high levels of pesticide within the spring snowpack:

- The greatest quantities of pesticides are used during spring and summer months on growing crops (Estellano et al., 2015).

- Pesticides can move from the sites where they are applied to the surrounding environment through drift during application and during post-application volatilisation from the soil (Taylor, 1978; Ferguson et al., 2014). Transport can occur at high altitudes because of the elevation of the boundary layer during the warm season, which enables the greater mixing of air masses (Ketterer et al., 2014).

- The meteorological conditions during this season (i.e., more frequent snowfall events and less wind ablation) result in the accumulation of a thicker snowpack (Kirchgeorg et al., 2016).

- The higher precipitation amounts in spring (Isotta et al., 2014) lead to more efficient scavenging of pesticides compared to late summer, when precipitation is less. Consequently, the spring snowpack has a higher input of CUPs.

Through these processes, the spring peak in pesticide concentrations observed in the meltwater samples results from the melting of snow deposited on the glacier, while pesticides stored in the underlying ice were detected during the late summer.

The Forni Glacier samples, which were collected more frequently during the melting period, are useful for understanding the release of pesticides from the ice-snow matrix. In these meltwater samples, after the initial peak during July, we observed a sudden decrease in pesticide concentrations during the summer (August) followed by a gradual but continuous decline into autumn, reaching the lowest detected levels in October.

In general, the discharge of organic contaminants from melting snow depends on the physical and chemical properties of the molecules and other factors related to the characteristics of the snowpack, which can be quite variable from site to site. Limiting the discussion to the chemical properties, Meyer et al. (2009) reported that water-soluble organic substances, such as herbicides belonging to the triazine class, are prevalently released at the beginning of the melting period, while chemicals that are preferentially sorbed onto particles are often released towards the end of the melting season. In the following sections, data are discussed in relation to these considerations for each pesticide compound.

\section{1. $C P Y$}

CPY can be considered a widespread contaminant that is detected even in remote environments, such as the Arctic (Hermanson et al., 2005; Hoferkamp et al., 2010) or mountainous areas (Hageman et al., 2006; Hageman et al., 2010; Santolaria et al., 2015; Ferrario et al., 2017a; Guida et al., 2018). As shown in Fig. 1, $\mathrm{CPY}$ dominated the contamination fingerprints of the Alpine glaciers. Indeed, accepting the variable concentrations of CPY in space and time, this compound was detected in all meltwater samples collected from the Alpine Arc glaciers during 2016.

The lowest CPY concentrations were detected in the Western

Table 2

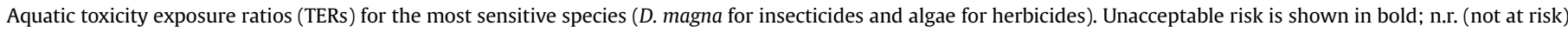
indicates that compounds were not detected.

\begin{tabular}{|c|c|c|c|c|c|c|c|c|}
\hline \multirow[t]{2}{*}{ Sampling Area } & \multirow[t]{2}{*}{ Date } & \multicolumn{7}{|c|}{ Toxicity Exposure Ratio } \\
\hline & & CPY & CPY-m & TBZ & d-TBZ & MTL & ALA & ATR \\
\hline \multirow[t]{2}{*}{ Lys } & $30 / 06 / 2016$ & 28 & 2220 & 8700 & n.r. & 39100 & 16900 & 86400 \\
\hline & $14 / 09 / 2016$ & 52.6 & 1300 & 16700 & 39200 & 50000 & n.r. & n.r. \\
\hline \multirow[t]{2}{*}{ Morteratsch } & 06/07/2016 & 6.48 & n.r. & 15000 & n.r. & n.r. & n.r. & n.r. \\
\hline & $15 / 09 / 2016$ & 14.8 & n.r. & n.r. & n.r. & n.r. & n.r. & n.r. \\
\hline \multirow[t]{5}{*}{ Forni } & $01 / 07 / 2016$ & 1.42 & 309 & n.r. & n.r. & 19600 & n.r. & n.r. \\
\hline & $02 / 08 / 2016$ & 4.82 & 234 & 5290 & n.r. & 37700 & n.r. & n.r. \\
\hline & $16 / 08 / 2016$ & 5.59 & n.r. & 4880 & n.r. & n.r. & n.r. & n.r. \\
\hline & 19/09/2016 & 12.6 & n.r. & n.r. & 39200 & n.r. & n.r. & n.r. \\
\hline & $06 / 10 / 2016$ & 14.6 & n.r. & n.r. & 116000 & n.r. & n.r. & n.r. \\
\hline \multirow[t]{2}{*}{ Presena } & $13 / 07 / 2016$ & 10.6 & n.r. & 4050 & n.r. & 9310 & n.r. & n.r. \\
\hline & $14 / 09 / 2016$ & 7.7 & n.r. & 23500 & 28600 & n.r. & n.r. & n.r. \\
\hline Tucket & $12 / 07 / 2016$ & 12 & n.r. & 9090 & 43500 & n.r. & n.r. & n.r. \\
\hline \multirow{2}{*}{ Giogo Alto } & $11 / 07 / 2016$ & 8.55 & n.r. & n.r. & n.r. & 6310 & n.r. & n.r. \\
\hline & 20/09/2016 & 10.2 & n.r. & n.r. & n.r. & 29100 & n.r. & n.r. \\
\hline
\end{tabular}


Alps (Lys Glacier). The concentrations measured during 2016 were in line with those found in the ice-core, indicating a consistent trend of contamination for this glacier (with the exception of 1997-1999 when peak concentrations occurred). In contrast, the highest CPY concentrations were measured in meltwater samples collected at the Forni Glacier, which peaked during July and then decreasing during the late summer/autumn months. In all other glacier meltwater samples collected in the Eastern Alps, CPY concentrations were intermediate (ranging from $6.75 \mathrm{ng} / \mathrm{L}$ to $20.7 \mathrm{ng} /$ L). This geographical pattern confirms and broadens the earlier findings of Ferrario et al. (2017a) from 2014; however, the concentrations reported here are generally higher. Variability in the concentrations of CPY has also been reported in samples collected in the Rocky Mountains (Hageman et al., 2006, 2010). According to these previous studies, agricultural land use, which can be considered a proxy for levels of pesticide application, was suggested as being important for explaining the presence and variable distribution of pesticides at remote sites.

The widespread distribution of CPY throughout the Alpine Arc can be partially explained by the physical and chemical properties and half-life of CPY, which influence its potential atmospheric transport. Mackay et al. (2014b), using the OECD Tool (Wegmann et al., 2009), produced a simple mass balance model which considers both physical and chemical properties and persistence of contaminants. Based on this, the calculated characteristic travel distance (CTD) for CPY is $280-300 \mathrm{~km}$. The CTD can be defined as the distance travelled by approximately two-thirds of a released chemical before its deposition and/or transformation.

Other studies have confirmed a CTD of $200-400 \mathrm{~km}$ for CPY (Muir et al., 2004; Hoferkamp et al., 2010; Ferrario et al., 2017a). This clearly indicates the potential for CPY to travel from the agricultural areas of the Po Valley to the Alps, less than $300 \mathrm{~km}$ away.

Previous studies have shown that pollutant emissions from the Po Valley strongly contribute to their accumulation in glaciers (Gabrieli et al., 2011; Villa et al., 2014; Kirchgeorg et al., 2016). Indeed, air masses, mainly originating from the south, favour the transport of pollutants up into the mountains, where daily cycles of upslope winds and valley breezes during the warm season contribute to their atmospheric transport and subsequent accumulation.

The valleys and foothills of the Eastern Alps are extensively cultivated to grow fruit trees on which CPY is applied. In the absence of consumption data for pesticides, sales data (regional scale) provide a good estimate of the quantities applied to crops. According to SIAN (2017), which reports sales volumes from 1996 to 2012, CPY is among the 10 most-used pesticides in Italy, and shows an increasing trend (Figure S-2). Regions with the highest use of CPY, in descending order, are Veneto $>$ Emilia Romagna $>$ Lombardy. The distance of these regions from the investigated glaciers is compatible with the estimated CTD of CPY. The high emission of CPY in the Po Valley contributes significantly to the widespread contamination of Alpine areas, while the variable geographical distribution of this contaminant might result from regional differences in its use.

In addition to these geographical trends, seasonal differences were also observed. For almost all of the investigated glaciers, the highest concentrations of CPY were measured during early summer. This pattern was previously highlighted by Ferrario et al. (2017a) and is related to the melting of the annual snowpack deposited on the glacier. Short concentration pulses in receiving water bodies have also been reported as a result of the melting snowpack (Hageman et al., 2006; Bizzotto et al., 2009; Shahpoury et al., 2014; Villa et al., 2014).

CPY shows intermediate partitioning properties and thus can be found in samples both in dissolved form and adsorbed onto particles. As previously explained, the CPY peak detected at the beginning of the spring/summer season was likely attributed to the dissolved CPY fraction, derived from the seasonal melting of the snowpack. Given its partitioning properties, the consistent presence of CPY throughout the summer season could be attributed either to the release of the fraction adsorbed to particles or dissolved fraction in melting glacial ice.

The periods during which contaminants are released from snow and ice in high-altitude zones are critical because melting often happens when organisms are at a vulnerable stage of development and during phases of intense biological activity (Meyer and Wania, 2008). Bioconcentration is considered the main chemical uptake process for macroinvertebrates (Bizzotto et al., 2009; Morselli et al., 2014) meaning that high concentrations of CPY could represent a hazard for these organisms.

\section{2. $C P Y-m$}

Unlike CPY, CPY-m was only found sporadically; CPY-m concentrations during 2016 were less than $1 \mathrm{ng} / \mathrm{L}$ for the Lys Glacier and only a few ng/L for the Forni Glacier. The presence of CPY-m in high mountains has rarely been studied (Guida et al., 2018) and to the best of our knowledge, the only data available are for Brazilian mountains where it was present at concentrations less than the limit of detection which is in contrast to CPY.

The lower application of this compound can be seen in the pesticide sales data (SIAN, 2017). It also has a low CTD (43 km; Marino, 2016) that limits its transport potential, which likely explains its detection only in some areas.

\section{3. $T B Z$ and $d-T B Z$}

The concentrations of TBZ ranged from $0.51 \mathrm{ng} / \mathrm{L}$ to $2.96 \mathrm{ng} / \mathrm{L}$. This compound was predominantly detected in those glaciers nearest to the maize cropping areas of the Po Valley, where this herbicide is widely applied.

Based on SIAN (2017), TBZ is used extensively in northern Italy, especially in Lombardy and Veneto (Figure S-3). With a CTD greater than $150 \mathrm{~km}$ (Marino, 2016), TBZ has the capacity to travel from these regions to more remote alpine sites. Indeed, previous research has highlighted the potential for the regional-scale atmospheric transport of triazines such as TBZ and atrazine (Bossan et al., 1995). The high solubility of TBZ coupled with high precipitation rates favour its scavenging, thus limiting the potential for atmospheric transport to more distal Alpine glaciers, such as the Giogo Alto Glacier, as previously observed by Petit et al. (1997) and Ferrario et al. (2017a).

As shown in Fig. 1, spatial and temporal differences in the concentrations of TBZ were also observed. The highest values for TBZ were detected at the beginning of the summer season. As previously described, water-soluble chemicals are usually washed out early in the melting season. Meyer et al. (2009) confirmed this for atrazine by demonstrating that over half of the compound is discharged within the first quarter of released meltwater. Because atrazine is also a $\mathrm{Cl}$-triazine, we can assume similar behaviour for TBZ.

A strong reduction in the concentration of TBZ was observed during late summer. In contrast, d-TBZ was the second most abundant chemical during late summer, with concentrations reaching $4 \mathrm{ng} / \mathrm{L}$. The formation of d-TBZ results from the degradation of its parent compound as facilitated by bacteria (Barra Caracciolo et al., 2001). This biotransformation could occur on the glaciers themselves by means of supraglacial bacteria in cryoconite holes, which are considered the most biologically active ecosystems on glaciers (Ferrario et al., 2017b). Conversely, transformation 
might occur in agricultural fields post-application followed by revolatilisation and transport to the glaciers.

\section{4. $M T L$}

MTL was found in meltwater samples from four of the six studied glaciers (the Lys, Forni, Presena, and Giogo Alto glaciers) at concentrations ranging from $0.86 \mathrm{ng} / \mathrm{L}$ to $6.81 \mathrm{ng} / \mathrm{L}$. Based on the average annual sales volume (SIAN, 2017), MTL is widely used in northern Italy, particularly in Lombardy and Veneto. Sales data also show that the volumes of MTL sold in these regions are similar to TBZ. In fact, the two herbicides are usually used on maize crops as a mixture at a ratio of $1: 1$; the concentrations of these two compounds in meltwater samples approximated a ratio of 1 (ranging from 0.6 to 2). For this reason, a common origin for these contaminants can be assumed.

The highest concentrations of MTL were detected for the Giogo Alto Glacier in July; however, TBZ was not detected on this glacier. This probably excludes the dual application of MTL and TBZ on maize in the Po Valley as the emission source. In addition to its use on maize when mixed with TBZ, sales data processed by the Austrian Agency for Health and Food Safety (Austrian Agency for Health and Food Safety (AGES), 2012) show that MTL is also applied on rapeseed, which might therefore represent an alternative source.

\subsection{Other herbicides}

Alachlor and atrazine were only detected in the meltwater sample gathered at the end of June from the Lys Glacier (at concentrations of $0.59 \mathrm{ng} / \mathrm{L}$ and $0.22 \mathrm{ng} / \mathrm{L}$, respectively). The use of these herbicides is now forbidden in Europe, meaning their presence in meltwater probably reflects their past use. Specifically, atrazine has been banned in Italy since the 1990s and in the EU since 2003, while alachlor was banned across Europe in 2006.

\subsection{Historical trends}

The analysis of ice chips collected from the Lys Glacier showed that the main contaminants across all years were CPY (concentrations ranging from $1 \mathrm{ng} / \mathrm{L}$ to $32 \mathrm{ng} / \mathrm{L}$ ) and TBZ (concentrations ranging from $1 \mathrm{ng} / \mathrm{L}$ to $2 \mathrm{ng} / \mathrm{L}$ ). This finding can be interpreted based on the historical regional use of these two pesticides (Fig. 2), particularly in Lombardy and Piedmont, which are the two regions closest to the sampling site and where the local air masses originate (Gabrieli et al., 2011).

A comparison of CPY and TBZ concentrations found in the ice samples and sales information shows that the concentration peaks correspond to a marked increase in sales; according to SIAN (2017), the average annual sales volume of CPY from 1996 to 2002 was 64 tonnes in Piedmont, peaking at 380 tonnes in 1999, and 23 tonnes in Lombardy. The peak in the sales during 1999 in Piedmont mirrored an increase in the concentrations of CPY in ice during the period 1997-1999.

TBZ has been intensively used for many years in the Po Valley, particularly following the ban of atrazine in 1990 (Bozzo et al., 2013), and it remains one of the most widely used pesticides in the Lombardy region. The average annual TBZ sales in Lombardy for the period 1996-2002 was 392 tonnes (SIAN, 2017). Sales peaked during 2002, reaching 1727 tonnes, reflected in a doubling of the concentrations found in the samples. Based on this, we hypothesise that the intense local use of TBZ on maize crops-the major crop type in the entire Po Valley-is mainly responsible for the contamination of ice in the study area.

Surprisingly, despite the intensive use of MTL in the Lombardy region and in Piedmont, and its presence in meltwater samples, this herbicide was not detected in the ice samples. Indeed, MTL has been intensively used worldwide since the 1990s, taking the place of atrazine in European maize cultivation. It is among the most applied pesticide in the Po Valley, with average annual sales of 207 tonnes in Lombardy and 78 tonnes in Piedmont-quantities that are very similar to TBZ. In contrast, the apparent absence of ALA, ATR, and CPY-m in the ice samples is likely attributable to the low volume of the melted ice and/or the very limited sales volumes (and thus application) of these compounds.

\subsection{Environmental risk assessment}

As reported in Section 3.3, TERs for CPY indicated an unacceptable level of risk for aquatic organisms living in the streams fed by the studied glaciers. This assessment does not substantially change if a different approach is taken based on toxicity data and species sensitivity distributions (SSDs). As specified in Giddings et al. (2014), the hazardous concentration of CPY for five percent of crustacean and insect species $\left(\mathrm{HC}_{5}\right)$ is $34 \mathrm{ng} / \mathrm{L}$ and $87 \mathrm{ng} / \mathrm{L}$, respectively. According to European Chemicals Agency (ECHA) procedures, when the SSD approach is applied, the trigger value can be lowered to 5 . With a few exceptions, the $\mathrm{HC}_{5} / \mathrm{MEC}$ ratios were always below this threshold for $D$. magna and, in many cases, for insects. For example, for the Forni Glacier, this ratio was constantly less than 5 for $D$. magna between July to October, as was frequently the case for insects, indicating some general risk to aquatic invertebrates.

The potential recovery of aquatic invertebrates exposed to CPY is strongly dependent on the time intervals between exposure events; the longer the period between exposures, the greater

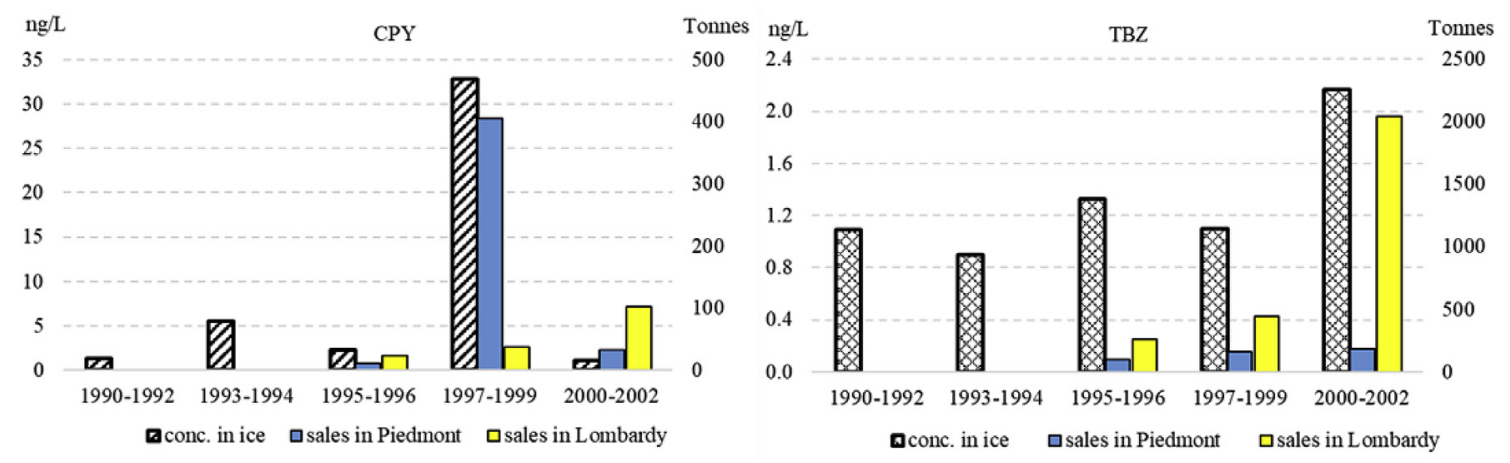

Fig. 2. Concentrations of pesticides in ice chips and sales volumes of CPY and TBZ in Piedmont and Lombardy. 
degree of detoxification and excretion of CPY can occur. Indeed, Giddings et al. (2014) indicated that the recovery time of the target enzyme AChE ranges between 1 and 7 days. Based on the risk ratios for the Forni Glacier, the probability of recovery for invertebrates is significantly reduced. This is supported by Morselli et al. (2014) who modelled the release of contaminants from glaciers on an hourly basis and highlighted that the discharge of pollutants occurs continuously during the melting season.

According to Clements et al. (2012), the structure of communities naturally varies along environmental gradients and, consequently, their responses to chemical stressors may be equally variable. Specifically, these authors stressed that the structure and composition of macroinvertebrate communities naturally vary from headwater streams to larger rivers, and suggested that headwater communities are more sensitive than those in higherorder reaches. These differences may reflect the preadaptation of communities in naturally disturbed and highly variable environments (Rapport, 1995), including higher-order river reaches where pesticides are typically applied for agriculture. On this basis, while water quality in lowland rivers may recover from pollution events over a relatively short period of time, recovery in headwater streams may require a much longer period.

In the EU, the evaluation of the fate of pesticides in the air follows the FOCUS AIR guidelines (FOCUS, 2008). Although atmospheric transport distances for pesticides are defined (short-range: $<1 \mathrm{~km}$; medium-range: 1-1000 km; long-range: $>1000 \mathrm{~km}$ ), these guidelines provide no suggestions for evaluating exposure via the medium-range atmospheric transport (MRAT) processes that are most relevant to this study. This limitation is acknowledged by the FOCUS AIR working group, which suggests that more research is required on MRAT to inform future toxicology exposure assessments.

\section{Conclusions}

The occurrence of pesticides in Alpine glaciers supports the hypothesis that seemingly pristine areas are subject to the accumulation of contaminants originating from agricultural areas, and that this poses potential risks to high-altitude aquatic ecosystems. For the glacier environments studied here, we found that CPY exceeded the acceptable risk threshold during the melting season. This suggests that MRAT processes should be considered in EU regulations for pesticides to protect the water quality of alpine aquatic communities. Indeed, our results reinforce the conclusions of the FOCUS AIR working group, highlighting the lack of tools available for the full evaluation of pesticide exposure in alpine environments.

\section{Author contribution}

CR: Methodology, Formal Analysis, Validation, Data curation. AF: Conceptualization, Resources, Writing- Reviewing and Editing, Supervision, Funding Acquisition. VM: Methodology, Investigation. SV: Conceptualization, Writing- Reviewing and Editing, Supervision, Funding Acquisition.

\section{Acknowledgements}

This work was supported by the Cassa di Risparmio di Trento e Rovereto Foundation (CARITRO n. Rif. Int.: 2015.0199; 2015-2018) and the University of Milano Bicocca (Fondo di Ateneo - QUOTA COMPETITIVA - n. Rif. 2016-ATESP-0044 and Fondo d'Ateneo).

We would like to thank Valeria Lencioni, Andrea Franzetti, Claudia Ferrario, and Pietro Fumagalli for helping during sample collection.

\section{Appendix A. Supplementary data}

Supplementary data to this article can be found online at https://doi.org/10.1016/j.envpol.2019.02.067.

\section{References}

Austrian Agency for Health and Food Safety (AGES), 2012. Pflanzenschutzmittel Verwendungsstatistik: Verwendete Wirkstoffe in ausgewählten Kulturen und in Verkehr gebrachte. Menge im Jahr 2012. https://www.ages.at/download/0/0/ 3782780d49d53afc0512c9ab2f78fdb306b1d7df/fileadmin/AGES2015/Themen/ Pflanzenschutzmittel_Dateien/Pflanzenschutzmittel_Verwendungsstatistik_ 2012.pdf.

Barra Caracciolo, A., Giuliano, G., Di Corcia, A., Crescenzi, C., Silvestri, C., 2001. Microbial degradation of terbuthylazine in surface soil and subsoil at two different temperatures. Bull. Environ. Contam. Toxicol. 67, 815-820. https://doi.org/10. $1007 /$ s001280195.

Bizzotto, E.C., Villa, S., Vaj, C., Vighi, M., 2009. Comparison of glacial and non-glacialfed streams to evaluate the loading of persistent organic pollutants through seasonal snow/ice melt. Chemosphere 74, 924-930. https://doi.org/10.1016/j. chemosphere.2008.10.013.

Bossan, D., Wortham, H., Masclet, P., 1995. Atmospheric transport of pesticides adsorbed on aerosols I. Photodegradation in simulated atmosphere. Chemosphere. https://doi.org/10.1016/0045-6535(94)00372-2.

Bozzo, S., Azimonti, G., Villa, S., Di Guardo, A., Finizio, A., 2013. Spatial and temporal trend of groundwater contamination from terbuthylazine and desethylterbuthylazine in the Lombardy Region (Italy). Environ. Sci. Process. Impacts 15, 366-372. https://doi.org/10.1039/c2em30536d.

Calamari, D., Bacci, E., Focardi, S., Gaggi, C., Morosini, M., Vighl, M., 1991. Role of plant biomass in the global environmental partitioning of chlorinated hydrocarbons. Environ. Sci. Technol. 25, 1489-1495. https://doi.org/10.1021/ es00020a020.

Calamari, D., Tremolada, P., Di Guardo, A., Vighi, M., 1994. Chlorinated hydrocarbons in pine needles in Europe: fingerprint for the past and recent use. Environ. Sci. Technol. 28, 429-434. https://doi.org/10.1021/es00052a014.

Clements, W.H., Hickey, C.W., Kidd, K.A., 2012. How do aquatic communities respond to contaminants? It depends on the ecological context. Environ. Toxicol. Chem. https://doi.org/10.1002/etc.1937.

Daly, G.L., Wania, F., 2005. Organic contaminants in mountains. Environ. Sci. Technol. 39, 385-398. https://doi.org/10.1021/es048859u.

Daughton, C.G., 2003. Cradle-to-cradle stewardship of drugs for minimizing their environmental disposition while promoting human health. I. Rationale for and avenues toward a green pharmacy. Environ. Health Perspect. 111 (5), 754-774.

Estellano, V.H., Pozo, K., Efstathiou, C., Pozo, K., Corsolini, S., Focardi, S., 2015. Assessing levels and seasonal variations of current-use pesticides (CUPs) in the Tuscan atmosphere, Italy, using polyurethane foam disks (PUF) passive air samplers. Environ. Pollut. 205, 52-59.

European Commission (EC), 2009a. Directive 2009/128/EC of the European Parliament and of the council of 21 October 2009 establishing a framework for community action to achieve the sustainable use of pesticides. Off. J. Eur. Union. L 309/71.

European Commission (EC), 2009b. Regulation No 1107/2009 of 21 October 2009 of the European Parliament and of the Council concerning the placing of plant protection products on the market and repealing Council Directives 79/117/EEC and 91/414/EEC. Orkesterjournalen L 309, 1-50, 24.11.2009.

European Food and Safety Agency (EFSA), 2013. Guidance on tiered risk assessment for plant protection products for aquatic organisms in edge-of-field surface waters. EFSA J. 11 (7), 3290. https://doi.org/10.2903/j.efsa.2013.3290, 2013268 pp.

Ferguson, J.C., Hewitt, A.J., Eastin, J.A., Connell, R.J., Roten, R.L., Kruger, G.R., 2014 Developing a comprehensive drift reduction technology risk assessment scheme. J. Plant Protect. Res. 54 (1), 85-89. https://doi.org/10.2478/jppr-20140013.

Ferrario, C., Finizio, A., Villa, S., 2017a. Legacy and emerging contaminants in meltwater of three Alpine glaciers. Sci. Total Environ. 574, 350-357. https://doi. org/10.1016/j.scitotenv.2016.09.067.

Ferrario, C., Pittino, F., Tagliaferri, I., Gandolfi, I., Bestetti, G., Azzoni, R.S., Diolaiuti, G., Franzetti, A., Ambrosini, R., Villa, S., 2017b. Bacteria contribute to pesticide degradation in cryoconite holes in an Alpine glacier. Environ. Pollut. 230, 919-926. https://doi.org/10.1016/j.envpol.2017.07.039.

FOrum for Co-ordination of pesticide fate models and their Use (FOCUS), 2008. Pesticides in air: considerations for exposure assessment. Report of the FOCUS Working Group on Pesticides in Air. EC Document Reference SANCO/10553/ 2006 Rev 2, p. 327. June 2008.

Gabrieli, J., Carturan, L., Gabrielli, P., Kehrwald, N., Turetta, C., Cozzi, G., Spolaor, A., Dinale, R., Staffler, H., Seppi, R., Dalla Fontana, G., Thompson, L., Barbante, C., 2011. Impact of Po Valley emissions on the highest glacier of the Eastern European Alps. Atmos. Chem. Phys. 11, 8087-8102. https://doi.org/10.5194/acp11-8087-2011.

Giddings, J.M., Williams, W.M., Solomon, K.R., Giesy, J.P., 2014. Risks to aquatic organisms from use of chlorpyrifos in the United States. Rev. Environ. Contam. Toxicol. https://doi.org/10.1007/978-3-319-03865-0_5.

Guida, Y.D.S., Meire, R.O., Torres, J.P.M., Malm, O., 2018. Air contamination by legacy 
and current-use pesticides in Brazilian mountains: An overview of national regulations by monitoring pollutant presence in pristine areas. Environ. Pollut. 242, 19-30. https://doi.org/10.1016/j.envpol.2018.06.061.

Hageman, K.J., Simonich, S.L., Campbell, D.H., Wilson, G.R., Landers, D.H., 2006. Atmospheric deposition of current-use and historic-use pesticides in snow at National Parks in the Western United States. Environ. Sci. Technol. 40, 3174-3180. https://doi.org/10.1021/es060157c.

Hageman, K.J., Hafner, W.D., Campbell, D.H., Jaffe, D.A., Landers, D.H. Simonich, S.L.M., 2010. Variability in pesticide deposition and source contributions to snowpack in western U.S. national parks. Environ. Sci. Technol. 44, 4452-4458. https://doi.org/10.1021/es100290q.

Hermanson, M.H., Isaksson, E., Teixeira, C., Muir, D.C.G., Compher, K.M., Li, Y.F., Igarashi, M., Kamiyama, K., 2005. Current-use and legacy pesticide history in the Austfonna ice cap, Svalbard, Norway. Environ. Sci. Technol. 39, 8163-8169. https://doi.org/10.1021/es051100d.

Hoferkamp, L., Hermanson, M.H., Muir, D.C.G., 2010. Current use pesticides in Arctic media; 2000-2007. Sci. Total Environ. 408, 2985-2994. https://doi.org/10.1016/ j.scitotenv.2009.11.038.

Isotta, F.A., Frei, C., Weilguni, V., Perčec Tadič, M., Lasségues, P., Rudolf, B., Pavan, V., Cacciamani, C. Antolini, G., Ratto, S.M., Munari, M., Micheletti, S., Bonati, V. Lussana, C., Ronchi, C., Panettieri, E., Marigo, G., Vertačnik, G., 2014. The climate of daily precipitation in the Alps: Development and analysis of a highresolution grid dataset from pan-Alpine rain-gauge data. Int. J. Climatol. 34 (5), 1657-1675. https://doi.org/10.1002/joc.3794.

Ketterer, C., Zieger, P., Bukowiecki, N., Collaud Coen, M., Maier, O., Ruffieux, D., Weingartner, E., 2014. Investigation of the planetary boundary layer in the Swiss Alps using remote sensing and in-situ measurements. Boundary-Layer Meteorol. 151, 317-334. https://doi.org/10.1007/s10546-013-9897-8.

Kirchgeorg, T., Dreyer, A., Gabrielli, P., Gabrieli, J., Thompson, L.G., Barbante, C., Ebinghaus, R., 2016. Seasonal accumulation of persistent organic pollutants on a high altitude glacier in the Eastern Alps. Environ. Pollut. 218, 804-812. https:// doi.org/10.1016/j.envpol.2016.08.004.

Lewis, K.A., Tzilivakis, J., Warner, D., Green, A., 2016. An international database for pesticide risk assessments and management. Hum. Ecol. Risk Assess. Int. J. 22 (4), 1050-1064. https://doi.org/10.1080/10807039.2015.1133242.

Mackay, D., Hughes, D.M., Romano, M.L., Bonnell, M., 2014a. The Role of Persistence in Chemical Evaluations. Integrated Environ. Assess. Manag. 10 (4), 588-594. https://doi.org/10.1002/ieam.1545.

Mackay, D., Giesy, J.P., Solomon, K.R., 2014b. Fate in the Environment and LongRange Atmospheric Transport of the Organophosphorus Insecticide, Chlorpyrifos and Its Oxon. Rev. Environ. Contam. Toxicol. 231, 35-76. https://doi.org/10. 1007/978-3-319-03865-0.

Marino, G., 2016. Valutazione del rischio ambientale dei contaminanti emergenti in torrenti alpini. Graduation thesis in Environmental Sciences. University of Milano Bicocca.

Meyer, T., Wania, F., 2008. Organic contaminant amplification during snowmelt. Water Res. 42, 1847-1865. https://doi.org/10.1016/j.watres.2007.12.016.

Meyer, T., Lei, Y.D., Muradi, I., Wania, F., 2009. Organic contaminant release from melting snow. 2. Influence of snow pack and melt characteristics. Environ. Sci. Technol. 43, 663-668. https://doi.org/10.1021/es8020233.
Morselli, M., Semplice, M., Villa, S., Di Guardo, A., 2014. Evaluating the tempora variability of concentrations of POPs in a glacier-fed stream food chain using a combined modeling approach. Sci. Total Environ. 493, 571-579. https://doi.org/ 10.1016/j.scitotenv.2014.05.150.

Muir, D.C.G., Teixeira, C., Wania, F., 2004. Empirical and modeling evidence of regional atmospheric transport of current-use pesticides. Environ. Toxicol. Chem. 23, 2421-2432. https://doi.org/10.1897/03-457.

Muir, D.C.G., Teixeira, C.A., Alaee, M., Hermanson, M., 2007. Persistent organohalogens and current use pesticides in remote lake waters, sediments and icecaps. In: Castro-Jiménez, Eisenreich, Vives (Eds.), Persistent Organic Pollutants (POPs) in the European Atmosphere: An Updated Overview Institute for Environment and Sustainability, EUR 22876 EN, pp. 88-95.

Petit, V., Fontaine, H., Masclet, P., 1997. Atmospheric transport of pesticides II field study. Toxicol. Environ. Chem. 58, 1-15. https://doi.org/10.1080/ 02772249709358393.

Rapport, D.J., 1995. Ecosystem Health: An Emerging Integrative Science. In: Rapport, D.J., Gaudet, C.L., Calow, P. (Eds.), Evaluating and Monitoring the Health of Large-Scale Ecosystems. NATO ASI Series (Series I: Global Environmental Change), vol. 28. Springer, Berlin, Heidelberg.

Santolaria, Z., Arruebo, T. Pardo, A., Matesanz, J.M., Bartolomé, A., Caixach, J. Lanaja, F.J., Urieta, J.S., 2015. Evaluation of airborne organic pollutants in a Pyrenean Glacial Lake (The Sabocos Tarn). Water Air Soil Pollut. 226, 226-383. https://doi.org/10.1007/s11270-015-2648-3.

Shahpoury, P., Hageman, K.J., Matthaei, C.D., Alumbaugh, R.E., Cook, M.E., 2014 Increased concentrations of polycyclic aromatic hydrocarbons in alpine streams during annual snowmelt: Investigating effects of sampling method, site characteristics, and meteorology. Environ. Sci. Technol. 48, 11294-11301. https://doi. org/10.1021/es502999e.

Italian Agricultural Information System (SIAN), 2017. Riepiloghi dichiarazioni di vendita dei prodotti fitosanitari (D.P.R. n. 290/2001 art. 42). http://www.appa. provincia.tn.it/fitofarmaci/programmazione_dei_controlli_ambientali/-Criteri_ vendita_prodotti_fitosanitari/.

Taylor, A.W., 1978. Post application volatilization of pesticides under field conditions. J. Air Pollut. Contr. Assoc. 17, 277-283.

Villa, S., Maggi, V., Negrelli, C., Finizio, A., Bolzacchini, E., Vighi, M., 2001. Historica profile of polychlorinated biphenyls (PCBs) in an Alpine Glacier. Fresenius Environ. Bull. 10, 711-716.

Villa, S., Vighi, M., Maggi, V., Finizio, A., 2003. Historical trends of organochlorine pesticides in an Alpine Glacier. J. Atmos. Chem. 46, 295-311. https://doi.org/10. 1023/A:1026316217354.

Villa, S., Negrelli, C., Maggi, V., Finizio, A., Vighi, M., 2006. Analysis of a firn core for assessing POP seasonal accumulation on an Alpine glacier. Ecotoxicol. Environ. Saf. 63, 17-24. https://doi.org/10.1016/j.ecoenv.2005.05.006.

Villa, S., Vighi, M., Finizio, A., 2014. Theoretical and experimental evidences of medium range atmospheric transport processes of polycyclic musk fragrances. Sci. Total Environ. 481, 27-34. https://doi.org/10.1016/j.scitotenv.2014.02.017.

Wegmann, F., Cavin, L., MacLeod, M., Scheringer, M., Hungerbühler, K., 2009. The OECD software tool for screening chemicals for persistence and long-range transport potential. Environ. Model. Softw. https://doi.org/10.1016/j.envsoft. 2008.06.014. 